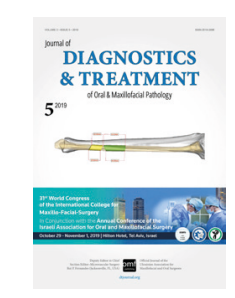

Editorial

\title{
Every Hashtag Matters: An Importance of That Instagram Tool in a Life of the Peer-Reviewed Journal
}

\author{
João Luiz Gomes Carneiro Monteiro and levgen I. Fesenko ${ }^{b}$
}

\author{
Every person matters. \\ - Tom Hanks as James Donovan \\ in movie "Bridge of Spies"
}

Hashtag (ie, the \# symbol) ${ }^{1}$ is a type of metadata tag used in the different social media, such as Instagram, Twitter, YouTube, etc. It was invented by Chris Messina in 2007, when he proposed to use hashtag in Twitter with a purpose to group and easily find posts with a specific content/theme. Scientific journals from different specialties with high Impact Factor are also paying a great attention to the role of hashtags in their journals ' media accounts lifes. ${ }^{1,}$

The DTJournal's first Instagram-related international collaboration started in 2017, during the $23^{\text {rd }}$ International Conference on Oral and Maxillofacial Surgery in Hong Kong. Using in DTJournal's account the hashtag \#icoms2017 (which included 164 posts) two participants of the event Dr. Monteiro and Dr. Fesenko began a productive conversation dedicated to submission of a case report article. $^{3}$ Which was successfully published (Fig) in the nearest issue.

So, an Editorial's message to the colleagues is very

\footnotetext{
a Maxillofacial Surgeon, PhD Student, University of Pernambuco, Recife, Pernambuco, Brazil.

Web \& Social Media Editor, DTJournal.

' Managing Editor, DTJournal.

E-mails: joaoluizgcm2@gmail.com (João Luiz Monteiro)

i.i.fesenko@dtjournal.org (levgen Fesenko)

Instagram: joaoluizmonteiro$$
\text { dr_eugenfesenko }
$$

http://dx.doi.org/10.23999/j.dtomp.2019.5.1.

(c) 2019 OMF Publishing, LLC. This is an open access article under the CC BY licence (http://creativecommons.org/licenses/by-nc/4.0/).
}

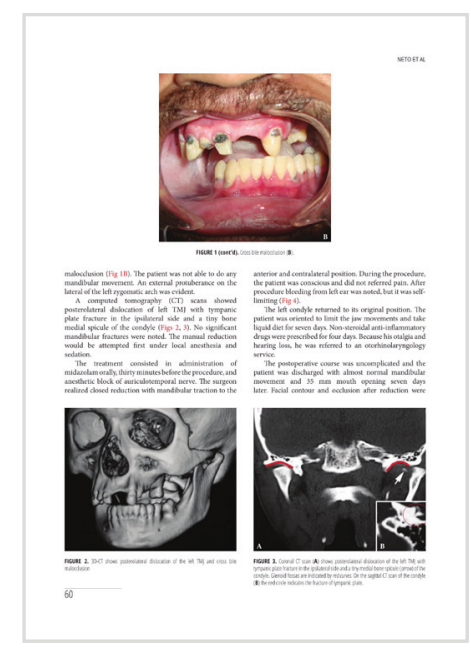

FIGURE. Second page of the article of Neto et al.

clear: Do not regret the time to use hashtags in all kind of scientific, communicative or marketing purposes.

\section{REFERENCES}

1. Rauschnabel, PA, Sheldon, P, Herzfeldt, E. What motivates users to hashtag on social media? Psychol Mark 2019;36:473-88. https://doi.org/10.1002/ mar.21191.

2. Dorfman RG, Vaca EE, Mahmood E, Fine NA, Schierle CF. Plastic surgery-related Hashtag utilization on Instagram: implications for education and marketing. Aesthet Surg J 2018;38:332-8. https://doi.org/10.1093/ asj/sjx120.

3. Neto AMR, Monteiro JL, Borba PM, Melo AR, Barbosa LM, Vasconcelos BC. TMJ's posterolateral dislocation with tympanic plate fracture - case report. J Diagn Treat Oral Maxillofac Pathol 2017;1:59-64. https://doi.org/10.23999/j.dtomp.2017.2.2. 